\title{
Study on Logistics Efficiency of Key Provinces and Cities along the "Belt and Road"
}

\author{
Weibin LIN ${ }^{1, a}$, Yingyi HUANG ${ }^{1,2, b, *}$ \\ ${ }^{1}$ TSL School of Busines,Quanzhou Normal University,Quanzhou , China \\ ${ }^{2}$ The Cloud Computing \& Internet of Things \& Electronic Commerce University \\ Engineering Center in Fujian Province, Quanzhou, China \\ alwbin1990@vip.qq.com \\ b, ${ }^{*}$ huangyingyi31@163.com \\ ${ }^{*}$ Corresponding author
}

Keywords: “Belt and Road” , Logistics efficiency, Data envelopment analysis.

\begin{abstract}
According to the "Belt and Road" initiative, the logistics efficiency determine the operating costs of logistics directly, and indirectly influence the competitiveness of China's export commodities internationally. In this paper,DEA method is used to study the logistics efficiency of eighteen key provinces in China. And the result shows that the overall average of logistics efficiency to some provinces is relatively low, except other five provinces and cities, which can provide policy guidance for the "Belt and Road" development strategy.
\end{abstract}

\section{Introduction}

Chinese President Xi Jinping proposed “One Belt One Road"strategy in 2013, which can construct the muti-layered and compound network of sea and land with many continents-Asia, Africa and Europe, and promote cooperation, communication and development among countries and regions along the route $^{[1,2]}$.And China involves eighteen provinces, cities and municipalities. The logistics efficiency directly influences logistic cost. In order to make full use of the relative advantages of each region and actively integrate into the "One Belt One Road"significant development strategy, higher requirements have been put forward for the provinces and cities along the line.

\section{Evaluation methodology}

Most computational methods of studying logistics efficiency are based on the ratio between input and output of materials at present ${ }^{[3,4]}$.And there are some methods such as $\mathrm{ABC}$ cost method, index tree method, AHP method, DEA method commonly used to evaluate the logistics efficiency ${ }^{[3-11]}$.But ABC only applies to the influential analysis of single variable, index tree method has poor integrality and hardly reflects on the changes of the logistics efficiency in general. And AHP method needs a few quantitative information, has strong subjectivity, which results tend to be less objective. However, DEA method rightly avoids subjectivity, simplifies the calculation and reduces errors. Accordingly, DEA method is used as a research method in this paper. The specific information are as follows.

\subsection{CCR model}

It is supposed to have $\mathrm{n}$ decision-making units(DMU) which are comparable and belong to one type. And each DMU has $m$ input and $s$ output. Then we can get the model as follows by using linear programming and duality transformation methods.

$$
D(\varepsilon)=\min \left[\theta-\varepsilon\left(e^{-} S^{-}+e^{+} S^{+}\right)\right]
$$




$$
\text { s.t. }\left\{\begin{array}{l}
\sum_{j=1}^{n} X_{j} \lambda_{j}+S^{-}=\theta X_{0} \\
\sum_{j=1}^{n} Y_{j} \lambda_{j}-S^{+}=Y_{0} \\
\lambda_{j} \geq 0, j=1,2 \ldots n \\
S^{+}=\left(s_{1}^{+}, s_{2}^{+} \ldots s_{s}^{+}\right)^{T} \geq 0, S^{-}=\left(s_{1}^{-}, s_{2}^{-} \ldots s_{m}^{-}\right)^{T} \geq 0
\end{array}\right.
$$

Where $\theta, \lambda_{\mathrm{j}} j=1,2, \ldots, n$ are all dual variables, $m$ is the unit vector. $\mathrm{e}^{-}=(1,1, \ldots, 1) \in E_{m}, s$ is the unit vector $\mathrm{e}^{+}=(1,1, \ldots, 1) \in E_{s}$. S+ and s- are slack variables, $X_{j}=\left(x_{1 j}, x_{2 j} \ldots x_{m j}\right)^{T}, Y_{j}=\left(y_{1 j}, y_{2 j} \ldots y_{s j}\right)^{T}$, $X_{0}=\left(x_{i j_{0}}, x_{2 j_{0}} \ldots x_{m j_{0}}\right)^{T}, Y_{0}=\left(y_{1 j_{0}}, y_{2 j_{0}} \ldots y_{s j_{0}}\right)^{T}$.

\subsection{BCC model}

CCR model exists certain limitation, because it is based on the assumed condition which is constant returns to scale to evaluate the comparative efficiency ${ }^{[5-7]}$. Thus, a new BCC model is constructed as follows by changing the hypothetical condition about constant returns to scale. It is assumed that constant returns to scale changes to be variable, and constraint condition $\sum_{j=1}^{\mathrm{n}} \lambda_{j}=1$ is adde, we can get the input-oriented BCC model ${ }^{[5,6]}$ :

$$
\begin{aligned}
\mathrm{V}(\varepsilon)=\min & \left.\theta-\varepsilon\left(e^{-} S^{-}+e^{+} S^{+}\right)\right] \\
\text {s.t. } & {\left[\begin{array}{l}
\sum_{j=1}^{n} X_{j} \lambda_{j}+S^{-}=\theta X_{0} \\
\sum_{j=1}^{n} Y_{j} \lambda_{j}-S^{+}=Y_{0} \\
\sum_{j=1}^{n} \lambda_{j}=1 \\
\lambda_{j} \geq 0, j=1,2 \ldots n \\
S^{+}=\left(s_{1}^{+}, s_{2}^{+} \ldots s_{s}^{+}\right)^{T} \geq 0, S^{-}=\left(s_{1}^{-}, s_{2}^{-} \ldots s_{m}^{-}\right)^{T} \geq 0
\end{array}\right.}
\end{aligned}
$$

Where $\lambda^{0}, S^{0-}, S^{0+}, \theta^{0}$ are the optimum value. If $\theta^{0}=1$, and $S^{0-}=S^{0+}=0$,DMU is valid both on technique and scale; else if $\theta^{0}=1, S^{0-}=0$,or $S^{0+}=0$,DMU is weakly efficient, but not valid on technique and scale at the same time; else if $\theta^{0}<1$,DMU is the non-efficient unit.

\section{Empirical research}

The paper has selected the indexes include X1(Unit million)=Logistics Employees' number, X2(Unit billion yuan)=Logistics Employees' salary, X3(Unit billion yuan)=Logistics Investment, X4(Unit ten thousand kilometers)=Grade Highway Mileage, Y1(Unit million tons)=Freight Turnover, Y2(Unit billion yuan)=Logistics Added Value, Y3(Unit billion yuan)=GDP, etc from various domestic and foreign literature ${ }^{[3-9]}$. And also chooses 18 key provinces and cities along the "Belt and Road" as DMU according to the indexes above. The relevant data mainly comes from China Statistic Yearbook and each province and cities Statistic Yearbook in 2016 published by National Bureau of Statistics, just as follows.

Table 3-1 Data of 18 Key Provinces along “One Belt One Road”in 2015

\begin{tabular}{|c|c|c|c|c|c|c|c|}
\hline \multirow{2}{*}{ Province } & \multicolumn{4}{|c|}{ Input Indexes } & \multicolumn{3}{c|}{ Output Indexes } \\
\cline { 2 - 8 } & $\mathrm{X} 1$ & $\mathrm{X} 2$ & $\mathrm{X} 3$ & $\mathrm{X} 4$ & $\mathrm{Y} 1$ & $\mathrm{Y} 2$ & $\mathrm{Y} 3$ \\
\hline Sinkiang & 16.7 & 133.9 & 1017.4 & 13.701 & 1772.94 & 536.06 & 9324.80 \\
\hline Tsinghai & 4.3 & 31.9 & 419.8 & 6.464 & 445.58 & 90.55 & 2417.05 \\
\hline Shaanxi & 28.0 & 177.6 & 1439.5 & 15.385 & 3263.52 & 713.02 & 18021.86 \\
\hline
\end{tabular}




\begin{tabular}{|c|c|c|c|c|c|c|c|}
\hline Gansu & 12.6 & 75.5 & 814.9 & 12.045 & 2225.81 & 274.65 & 6790.32 \\
\hline Ningxia & 3.8 & 23.9 & 261.7 & 3.305 & 816.93 & 200.66 & 2911.77 \\
\hline $\begin{array}{c}\text { Inner } \\
\text { Mongolia }\end{array}$ & 20.6 & 133.2 & 1251.2 & 16.377 & 4190.30 & 1087.32 & 17831.51 \\
\hline Heilongiiang & 27.5 & 162.4 & 995.0 & 13.633 & 1545.35 & 707.03 & 15083.67 \\
\hline Jilin & 16.6 & 97.0 & 961.3 & 9.009 & 1425.35 & 529.79 & 14063.13 \\
\hline Liaoning & 36.1 & 236.6 & 1263.6 & 10.651 & 11711.92 & 1702.80 & 28669.02 \\
\hline Guangxi & 20.0 & 124.0 & 1532.9 & 10.502 & 4061.82 & 803.10 & 16803.12 \\
\hline Yunnan & 17.1 & 112.9 & 1815.2 & 19.707 & 1500.27 & 304.49 & 13619.17 \\
\hline Tibet & 0.9 & 6.4 & 346.9 & 5.842 & 119.64 & 31.76 & 1026.39 \\
\hline Chongqing & 27.1 & 162.6 & 1436.5 & 11.289 & 2709.53 & 761.31 & 15717.27 \\
\hline Shanghai & 51.5 & 516.3 & 794.6 & 1.320 & 19495.88 & 1133.17 & 25123.45 \\
\hline Fujian & 24.5 & 161.0 & 2230.7 & 8.749 & 5447.49 & 1547.30 & 25979.82 \\
\hline Zhejiang & 32.0 & 239.8 & 2312.8 & 11.557 & 9869.72 & 1631.88 & 42886.49 \\
\hline Guangdong & 82.8 & 669.4 & 3037.6 & 20.146 & 14882.21 & 2928.90 & 72812.55 \\
\hline Hainan & 6.5 & 44.9 & 421.8 & 2.630 & 1181.73 & 187.80 & 3702.76 \\
\hline
\end{tabular}

\subsection{Calculation results}

It is calculated by using MaxDEA7.0 software based on CCR model and BCC model, and the results just as following table 3-2.

Table 3-2 Evaluation Form of Logistics Efficiency of 18 Provinces and Cities along the "One Belt One Road" in 2015

\begin{tabular}{|c|c|c|c|c|c|}
\hline No & Province & Comprehensive Efficiency & $\begin{array}{c}\text { Pure Technical } \\
\text { Efficiency }\end{array}$ & Scale Efficiency & Scale Merit \\
\hline 1 & Sinkiang & 0.5931 & 0.6114 & 0.9701 & Ascending \\
\hline 2 & Tsinghai & 0.4237 & 0.6930 & 0.6114 & Ascending \\
\hline 3 & Shaanxi & 0.6414 & 0.6763 & 0.9483 & Ascending \\
\hline 4 & Gansu & 0.6339 & 0.6650 & 0.9533 & Ascending \\
\hline 5 & Ningxia & 0.9555 & 1 & 0.9555 & Ascending \\
\hline 6 & Inner Mongolia & 0.9781 & 0.9812 & 0.9968 & Ascending \\
\hline 7 & Heilongjiang & 0.7052 & 0.7502 & 0.9401 & Ascending \\
\hline 8 & Jilin & 0.8107 & 0.8674 & 0.9346 & Ascending \\
\hline 9 & liaoning & 1 & 1 & 1 & Static \\
\hline 10 & Guangxi & 0.8242 & 0.8330 & 0.9894 & Ascending \\
\hline 11 & Yunnan & 0.6745 & 0.6786 & 0.9940 & Ascending \\
\hline 12 & Tibet & 0.8967 & 1 & 0.8967 & Ascending \\
\hline 13 & Chongqing & 0.6267 & 0.6362 & 0.9849 & Ascending \\
\hline 14 & Shanghai & 1 & 1 & 1 & Static \\
\hline 15 & Fujian & 1 & 1 & 1 & Static \\
\hline 16 & Zhejiang & 1 & 1 & 1 & Static \\
\hline 17 & Guangdong & 1 & 1 & 1 & Static \\
\hline 18 & Hainan & 0.5825 & 1 & 0.5825 & Ascending \\
\hline
\end{tabular}




\subsection{Results analysis}

\subsubsection{Comprehensive efficiency analysis}

According to table 3-2, there are five provinces' logistics comprehensive efficiency getting the optimum, they are Liaoning, Shanghai,Fujian, Zhejiang and Guangdong, indicating that the combination of input and output of logistics comprehensive efficiency has obtained the optimum, the logistic input has been made the greatest use and has received the best achievement which doesn't need any adjustment. In other 13 provinces like Heilongjiang, Inner Mongolia, Yunnan do not reach 1 ,meaning that they do not achieve the comprehensive efficiency.

\subsubsection{Pure technical efficiency analysis}

According to table 3-2, there are eight provinces' pure technical efficiency getting the optimum, they are Ningxia, Liaoning, Tibet, Shanghai, Fujian, Zhejiang, Guangdong and Hainan, indicating that their output in logistics compared with the input has reached the maximum, and the efficiency of logistic industry development is relatively high,but temporarily do not exist excess input or insufficient output. However, other three provinces' scale efficiency do not get the overall efficiency on the grounds that their production scale of logistic industry is small and is still in the stage of increasing returns to scale, they are Ningxia,Tibet and Hainan.

The pure technical efficiency of the rest ten provinces and cities has not reached the optimum, and even at the lower ranking provinces and cities, it has not reached 0.7,indicating that the logistic industry in these provinces is still using comparatively out-dated management styles, logistics technology, etc, and also has some deficiencies leading to the waste of logistics resources and lower logistics input efficiency. Because lower pure technical efficiency is the main reason for lower efficiency of logistics input and output, these provinces and cities need improvements in configuration and management of existing logistics resources, which have a great space to improve in efficiency.

\subsubsection{Scale efficiency analysis}

According to table 3-2,there are five provinces and cities- Liaoning, Shanghai, Fujian, Zhejiang, and Guangdong, their scale efficiency which equals 1 has not changed. And the scale efficiency of other provinces and cities is lower than 1,especially, the scale efficiency of Hainan (0.582) and Tsinghai (0.6114) is the lowest,far below the average scale efficiency. As a result, these two provinces are supposed to put more eyesight on adjusting the scale of logistics industry. And the scale merit of Liaoning, Shanghai, Fujian, Zhejiang and Guangdong has not changed, as to the remaining 13 provinces and cities, they are all at the stage of increasing returns to scale, which infers that it is advisable for these 13 provinces and cities to increase the input of logistics elements, to optimize the existing logistics modes, to strengthen the construction of logistics network system among regions, to promote the rapid and stable development of logistics industry and to enhance logistics scale efficiency.

\subsection{Slack variables of input and output}

In order to verify the validity of DEA calculation, we have calculated slack variables of logistics input and output of DEA invalid decision-making units. And results are obtained as the following table 3-3:

Table3-3 Slack Variables of Logistics Input and Output Indexes

\begin{tabular}{|c|c|c|c|c|c|c|c|c|}
\hline \multirow{2}{*}{ No } & \multirow{2}{*}{ Province } & \multicolumn{4}{|c|}{ Inputs Redundancy } & \multicolumn{3}{c|}{ Outputs Insufficient } \\
\cline { 3 - 9 } & & $s_{1}^{-}$ & $s_{2}^{-}$ & $s_{3}^{-}$ & $s_{4}^{-}$ & $s_{1}^{+}$ & $s_{2}^{+}$ & $s_{3}^{+}$ \\
\hline 1 & Sinkiang & -6.79 & -54.48 & -413.94 & -5.57 & 1006.61 & 0 & 0 \\
\hline 2 & Tsinghai & -2.48 & -18.39 & -241.95 & -3.73 & 110.67 & 1.42 & 0 \\
\hline 3 & Shaanxi & -10.04 & -63.69 & -516.25 & -5.52 & 1764.57 & 78.10 & 0 \\
\hline 4 & Gansu & -4.61 & -27.64 & -298.32 & -4.41 & 0 & 63.07 & 0 \\
\hline 5 & Ningxia & -0.17 & -1.06 & -11.65 & -0.15 & 77.81 & 0 & 459.97 \\
\hline 6 & Inner Mongolia & -0.45 & -2.92 & -27.39 & -0.36 & 1287.43 & 0 & 447.64 \\
\hline
\end{tabular}




\begin{tabular}{|c|c|c|c|c|c|c|c|c|}
\hline 7 & Heilongjiang & -8.11 & -47.87 & -293.32 & -4.02 & 3949.26 & 109.01 & 0 \\
\hline 8 & Jilin & -3.14 & -18.37 & -182.01 & -1.71 & 1811.08 & 5.33 & 0 \\
\hline 9 & liaoning & 0 & 0 & 0 & 0 & 0 & 0 & 0 \\
\hline 10 & Guangxi & -3.52 & -21.80 & -269.50 & -1.85 & 0 & 0 & 0 \\
\hline 11 & Yunnan & -5.57 & -36.75 & -590.84 & -6.41 & 1633.99 & 213.73 & 0 \\
\hline 12 & Tibet & -0.09 & -0.66 & -35.82 & -0.60 & 116.57 & 7.30 & 0 \\
\hline 13 & Chongqing & -10.12 & -60.71 & -536.31 & -4.21 & 1660.12 & 0 & 0 \\
\hline 14 & Shanghai & 0 & 0 & 0 & 0 & 0 & 0 & 0 \\
\hline 15 & Fujian & 0 & 0 & 0 & 0 & 0 & 0 & 0 \\
\hline 16 & Zhejiang & 0 & 0 & 0 & 0 & 0 & 0 & 0 \\
\hline 17 & Guangdong & 0 & 0 & 0 & 0 & 0 & 0 & 0 \\
\hline 18 & Hainan & -2.71 & -18.74 & -176.09 & -1.10 & 0 & 0 & 142.67 \\
\hline
\end{tabular}

PS: $\mathrm{s}_{\mathrm{i}}^{-}(\mathrm{i}=1,2,3,4)$ in this table refers to logistics employees,logistics employees' salary,logistics investment,and grade highway mileage; and $\mathrm{s}_{\mathrm{j}}{ }_{\mathrm{j}}(\mathrm{j}=1,2,3)$ refers to freight turnover,logistics value added and GDP.

Based on table 3-3,there are five provinces with valid DEA - Liaoning, Shanghai, Fujian, Zhejiang, and Guangdong, which inputs redundancy and outputs insufficient are zero and do not require adjustment. Other 13 provinces and cities with invalid DEA all have inputs redundancy and outputs insufficient. If they want to obtain the optimal efficiency, they have to adjust certain inputs and outputs,for instance, if Tsinghai wants to obtain the optimal logistics efficiency, under the existing circumstance of logistics resources input, it has to reduce logistics employees with 24.8 thousand people, logistics employees' salary with 1.838 billion yuan, logistics investment with 24.195 billion yuan and grade highway mileage with 37,300 kilometers, at the same time ,to increase freight turnover with 11.067 billion tons kilometers and logistics value added with 142 million yuan.

\section{Conclusion}

Through the empirical research on logistics efficiency of key provinces and cities along the "Belt and Road", we can draw the conclusion. Firstly, the overall development and efficiency of logistics is relatively low. Secondly, optimal logistics output can be obtained by optimizing the combination of factors of production. Thirdly, it is essential for provinces and cities which lack of logistics efficiency to introduce the advanced logistics technology and to improve logistics management modes and infrastructures.

\section{Acknowledgement}

This work is partially supported by the Natural Science Foundation of Fujian Province for Youths, China (Grant No. 2017J05116), the Natural Science Foundation of Fujian Province, China (Grant No. 2015J01286), the JK class project in Fujian Province Department of Education (Grant No. JK2014037), the Education Research Project of Fujian Province for Young and Middle-aged Teacher (Grant No. JAS150448). We deeply appreciate the organizations mentioned above.

\section{References}

[1] C.G. XIA, Analysis of the logistics performance level of the Silk Road Economic Belt, Market modernization,vol.24, pp. 36-37, 2016.

[2] W QING, Evaluation of logistics efficiency of maritime silk road in the new period, Journal of Commercial Economics, vol.9, pp. 79-81, 2016.

[3] M.Y. GUO, Study on Logistics Efficiency of Guangzhou Based on Super-efficiency DEA, Logistics Technology, vol.35, pp. 68-73, 2016. 
[4] C ZHANG, G.S. ZHANG, Z.J. ZHANG, Study on I/O Efficiency Evaluation of Logistics System of Jiangxi, Logistics Technology, vol.32, pp. 5-7, 2013.

[5] Z.D. LIAN, D.T. CHENG. The analysis of DEA model "Belt and Road" Initiative key provinces based on logistics efficiency, Journal of Commercial Economics, vol.4, pp. 80-82,2017.

[6] Z.Y. ZHANG. Analysis of China's modern logistics efficiency based on DEA, Modern Economic Information, vol.3, pp. 330-335,2017.

[7] X ZHANG, X.R. YANG, F WANG, Evaluation of logistics efficiency in New Silk Road Economic Belt-Based on the three stage DEA empirical analysis, Study and Practice, vol.5, pp. 21-32,2016.

[8] L WANG, G.L. XUE, H.L. ZHANG, Evaluation of Northern Xinjiang's Logistics Efficiency Based on a DEA Model, Resource Science, vol.36, pp. 1425-1433,2014.

[9] Y ZHANG, G.F. ZHANG, S.Q. XIE, Area Logistics Efficiency Analysis Based on DEA Model-Take the 14 Cities in Hunan Province for Empirical Analysis, Logistics Engineering and Management, vol.35, pp. 76-79,2013.

[10]X.P. LEI, Q Robin, S.F. LIU, Empirical Research on the Efficiency Measurement of Logistics Industry Based on DEA Model-Based on Input-output Data in 2008 from 31Provinces, Cities and Autonomous Regions of China, East China Economic Management, vol.26, pp. 62-66,2012.

[11]B.C. Ervural, B Ervural, S Zaim, Energy Efficiency Evaluation of Provinces in Turkey Using Data Envelopment Analysis, Procedia-Social and Behavioral Sciences, vol.235, pp. 139-148,2016. 